\title{
Effects of Violent Video Games on Aggressive Behavior, Helping Behavior, Aggressive Thoughts, Angry Feelings, and Physiological Arousal
}

\author{
Brad Bushman \\ Institute for Social Research, University of Michigan, \\ 426 Thompson Street, Ann Arbor, MI 48106, USA \\ bbushman@umich. edu \\ http: //www.umich. edu/ bbushman
}

\begin{abstract}
Meta-analytic procedures were used to review the results from 85 studies on violent video game effects. Violent video games increase aggressive behavior, aggressive thoughts, angry feelings, and arousal levels, and decrease helpful behaviors. The effects occurred for both children and adults and for both males and females. The more violent the video game, the stronger the effects. Violent video game effects are also increasing over time.
\end{abstract}

\section{References}

[1] Anderson, C. and Bushman, B., (2001). Effects of violent video games on aggressive behaviour, aggressive cognition, aggressive affect, physiological arousal, and pro-social behavior: a meta-analytic review of the scientific literature. Psychological Science, Vol. 12, No. 5, pp. 353-359.

[2] Anderson, C. and Bushman, B., (2002). Effects of media violence on society. Science, Vol. 295, No. 3, pp. 2377-2379. 